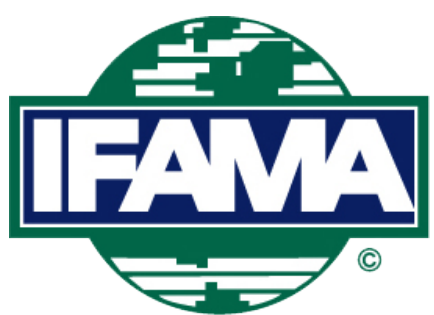

International Food and Agribusiness Management Review

Volume 24, Issue 6, 2021; DOI: 10.22434/IFAMR2021.x003

Special Issue: IFAMA 2020 Symposium

\title{
Advancing food and agribusiness management research: IFAMA 2020 best papers \\ EDITORIAL
}

\author{
Mustafa Hasanov ${ }^{\circledR a}$, Jacques Trienekens ${ }^{\mathrm{b}}$ and Wilfred Dolfsma ${ }^{\mathrm{c}}$ \\ ${ }^{a}$ Postdoctoral Researcher, ${ }^{b}$ Professor emeritus, ${ }^{c}$ Professor, Wageningen University \\ and Research, Hollandseweg 1, $6706 \mathrm{KN}$ Wageningen, the Netherlands
}

\begin{abstract}
This Special Issue presents the seven best papers from the $30^{\text {th }}$ IFAMA 2020 World Congress, reflecting the richness and quality of the agri-food business and management scholarship that IFAMA facilitates and promotes. They reveal the diversity of research topics and current practices related to the most pressing agri-food business and management issues. Whether the papers discuss vegetable producers cooperatives in Cambodia, innovation intermarries and enhancing collaboration in Sweden, or information nudges in ornamental plant labeling in the United States, the papers in this Special Issue illustrate the need for variegated professional and academic skills and expertise represented in IFAMA.
\end{abstract}

Keywords: agri-food management, agri-business, IFAMA, conference report, best papers JEL code: Q13, Q18, Q56, Y20

\footnotetext{
${ }^{\oplus}$ Corresponding author: mustafa.hasanov@wur.nl
} 


\section{Selected papers}

All papers were subject to vigorous double-blind reviews in several review rounds before being considered for publication, both when reviewed for inclusion in the IFAMA World Congress program and subsequently for inclusion in this Best Papers Special Issue. The selected papers, including the winner of the Best Paper prize, are:

- Bunthan Tray, Elena Garnevska, and Nicola Shadbolt: Linking smallholder producers to high-value markets through vegetable producer cooperatives in Cambodia (IFAMA 2020 Best Paper Competition winner).

- Edeoba Edobor, Renee Wiatt, and Maria Marshall: Keeping the farm business in the family: the case of farm and non-farm family businesses in the midwestern United States.

- Sirkka Schukat, Marie Diekmann and Heinke Heise: What links neuroscience to agricultural economics? A review of neuroscientific methods literature in agricultural economic research and marketing.

- Andreas Gabriel, Meike Rombach, Hannah Wieser, and Vera Bitsch: Got waste: knowledge, behavior, and self-assessment on food waste of university students in Germany.

- Hayk Khachatryan, Xuan Wei, and Alicia Rihn: Effects of pollinator-related information on consumer preference for neonicotinoid labeling.

- Lisa Blix Germundsson, Per Frankelius, and Charlotte Norrman: The role of innovation intermediary organisations in forming value creating meetings: the agri-food firm perspective.

- Kim Bryceson and Anne Ross: Performance and informality: the key to sustainability in small scale agri-food systems.

\section{Celebrating 30 years of IFAMR scholarship: the selected papers}

These articles should be briefly dwelled upon to reflect on their contributions and allow them to inform future research streams.

Tray et al. (2021) critically examine the importance of vegetable producer cooperatives in Cambodia in providing access to high-value or traditional markets. Using a mixed-method approach, the article highlights the different services producer cooperatives provide to cooperative members based on farmers' demographics, farm characteristics, marketing aspects, and institutional support. The authors argue that experiences related to vegetable farming and production matter the most when smallholder farmers decide to partake in high-value markets. Furthermore, the analysis reveals that the bigger the farm, the lower the likelihood to participate in high-value markets due to strict quality demands. The results of this article suggest that producer cooperatives that link farmers to traditional markets focus primarily on vegetable production. In contrast, cooperatives linking farmers to high-value markets focus on vegetable production, quality requirements, and business and marketing facilitation. The findings of this research could inform governmental, non-profit, and profit organizations in designing policies mechanism assisting smallholder producers in upgrading new production practices. Furthermore, managers and members of producer cooperatives could also benefit from training on business, management, and marketing skills to prepare them for highly competitive, high-value markets.

Edobor et al. (2021) present outstanding research comparing farm and non-farm family business succession planning for midwestern US farms. Using bivariate probit and logit models, the article looks at the effect of the owner, business, and family characteristics on two succession variables - the decision to keep the family business in the family and the transfer readiness of the business owners. The authors also explore the possibility that the decision to transfer could be based on the primary purpose of the business. The analysis suggests that if a farm appears to be successful, it is likely to remain within the family. Conversely, non-farm businesses tend to be passed on to owners outside the family. Based on the results, this research recommends that those who engage with family businesses find ways to engage and interact with a younger generation, whether in the family or the business from a very early stage, to smoothen succession planning. 
Schukat et al. (2021) draw on the intersection between the literature of neuroeconomics and agro-economic research to explore the possibilities for better understanding consumer decision behavior. Explorative in nature, the article presents novel theoretical frameworks based on neuroscientific research for explaining and predicting consumer purchasing behavior beyond classical willingness to pay studies. As the article argues, incorporating how humans make decisions by analyzing brain activities using advanced imagery and bioeconomic markers relates to the ability to process how humans make decisions between multiple choices and alternatives. While the theoretical implications of the article are based on a literature review, the practical implications will point the readers to the emerging world of novel methodological approaches to understanding human decision-making and agri-food practices.

Gabriel et al. (2021) analyzes the relationship between knowledge of food waste and students' behavior regarding food waste in Germany. Explorative in nature, the article also examines whether students tend to display social desirability bias when self-reporting on food waste behavior. The statistical analysis applied throughout the research indicates that students lack knowledge on food waste issues but display high interest in food topics and intent to avoid food waste. These findings illustrate the interest and awareness of the subject of food waste among German students and that, in general, students 'view themselves as superior to others in dealing with food waste across all phases of consumption' (Gabriel et al., 2021: 965). While provocative, such a statement indicates that behavior regarding food waste prevention is not necessarily based on knowledge but involvement in issues related to food waste and peer pressure recognizing food waste as a problem. The practical implications of the article are directed towards better information campaigns by regulatory bodies and consumer nudging by industry and retail to prevent food waste.

Khachatryan et al. (2021) employ a mixed logit model to examine how consumers rely on information treatments on neonicotinoids - a class of insecticides chemically similar to nicotine - in ornamental plants and how this information affects the willingness to pay of consumers. Building on food labeling literature and a choice-based internet survey on information treatments disclosing the presence or absence of harmful ingredients, their article argues that while negative information substantially affects consumer choices, balanced or unbiased information can effectively steer customers' perception. The take-home message is that consumers value the absence of neonicotinoids. Hence, the authors argue that it is likely that consumers are willing to change their product choice based on the information communicated to them. From a managerial standpoint, these findings suggest that regulatory authorities and businesses should devote more attention towards educating the public on the potential impacts of neonicotinoids insecticides on ecosystems.

Blix Germundsson et al. (2021) rely on document analysis, interviews, and insider accounts from intermediary organizations within the agri-food sector in Sweden to develop a comprehensive picture of what seems to be labeled as 'value creating meetings'. Building on literature on open innovation and organizational performance, the article investigates value-creating practices of three innovation intermediaries. The authors distill that two key ingredients are essential for enabling such meetings - a physical meeting place and a collaborative or innovative environment which translate to forming face-to-face meeting places and specific matchmaking practices between stakeholders. Implications for policy and praxis include sharpening the role of intermediary organizations in inter-organizational collaborations and allocating resources for training, mediation and negotiation.

Bryceson and Ross (2021) explore how small-scale supply chains in developing nations' contexts expanded beyond the local level and what roles performance and informality have in framing sustainability in smallscale agri-food systems. Juxtaposing the well-known tripe bottom layer approach and the notion of a habitus of informality, the article examines the informal and formal interplay between markets, communities, and institutions in Tonga and Solomon Islands horticultural products chains. The results suggest that in businesses rooted in small-scale societies, rules of kin and community are more important than clients or producers in establishing a sustainable supply chain. Hence, entrepreneurial activity, albeit present, is not profit but subsistence-oriented. While unsurprising, these findings resonate with ongoing calls for better integration of local knowledge and informal practices to understand what sustainability or doing business could mean. 


\section{IFAMA research tradition}

The research featured in this special is part of a legacy of research in the IFAMA line, nurturing top-notch research and fostering research by junior scholars and scholars from emerging economies. The emphasis within IFAMA is to push the boundaries of global knowledge in its domain yet strive for societal and sectoral impact simultaneously. This Special Issue thus is in line with the Special Issues from IFAMA World Congresses of previous years.

\section{References}

Blix Germundsson, L., P. Frankelius and C. Norrman. 2021. The role of innovation intermediary organisations in forming value creating meetings: the agri-food firm perspective. International Food and Agribusiness Management Review 24(6): 993-1004.

Bryceson, K.P. and A. Ross. 2021. Performance and informality: the key to sustainability in small scale agrifood systems. International Food and Agribusiness Management Review 24(6): 1005-1016.

Edobor, E.W., R.D. Wiatt and M.I. Marshall. 2021. Keeping the farm business in the family: the case of farm and non-farm family businesses in the midwestern United States. International Food and Agribusiness Management Review 24(6): 921-934.

Gabriel, A., M. Rombach, H. Wieser and V. Bitsch. 2021. Got waste: knowledge, behavior and self-assessment on food waste of university students in Germany. International Food and Agribusiness Management Review 24(6): 951-970.

Khachatryan, H., X. Wei and A. Rihn. 2021. Effects of pollinator related information on consumer preference for neonicotinoid labeling. International Food and Agribusiness Management Review 24(6): 971-991.

Schukat, S., M. Diekmann and H. Heise. 2021. What links neuroscience to agricultural economics? A review of neuroscientific methods literature in agricultural economic research and marketing. International Food and Agribusiness Management Review 24(6): 935-950.

Tray, B., E. Garnevska and N. Shadbolt. 2021. Linking smallholder producers to high-value markets through vegetable producer cooperatives in Cambodia. International Food and Agribusiness Management Review 24(6): 905-920. 